\title{
Comparative proteomic analysis reveals alterations in development and photosynthesis-related proteins in diploid and triploid rice
}

Shuzhen Wang ${ }^{1,2,3,4+}$, Wenyue Chen ${ }^{1 \dagger}$, Changdeng Yang ${ }^{2}$, Jian Yao ${ }^{3}$, Wenfei Xiao ${ }^{1}$, Ya Xin ${ }^{1}$, Jieren Qiu', Weimin $\mathrm{Hu}^{4}$, Haigen $\mathrm{YaO}^{3}$, Wu Ying ${ }^{1}$, Yaping $\mathrm{Fu}^{2}$, Jianxin Tong ${ }^{1}$, Zhongzhong Chen', Songlin Ruan ${ }^{1 *}$ and Huasheng $\mathrm{Ma}^{{ }^{*}}$

\begin{abstract}
Background: Polyploidy has pivotal influences on rice (Oryza sativa L.) morphology and physiology, and is very important for understanding rice domestication and improving agricultural traits. Diploid (DP) and triploid (TP) rice shows differences in morphological parameters, such as plant height, leaf length, leaf width and the physiological index of chlorophyll content. However, the underlying mechanisms determining these morphological differences are remain to be defined. To better understand the proteomic changes between DP and TP, tandem mass tags (TMT) mass spectrometry (MS)/MS was used to detect the significant changes to protein expression between DP and TP.

Results: Results indicated that both photosynthesis and metabolic pathways were highly significantly associated with proteomic alteration between DP and TP based on biological process and pathway enrichment analysis, and 13 higher abundance chloroplast proteins involving in these two pathways were identified in TP. Quantitative real-time PCR analysis demonstrated that 5 of the 13 chloroplast proteins ATPF, PSAA, PSAB, PSBB and RBL in TP were higher abundance compared with those in DP.

Conclusions: This study integrates morphology, physiology and proteomic profiling alteration of DP and TP to address their underlying different molecular mechanisms. Our finding revealed that ATPF, PSAA, PSAB, PSBB and RBL can induce considerable expression changes in TP and may affect the development and growth of rice through photosynthesis and metabolic pathways.
\end{abstract}

Keywords: Rice, Polyploidy, Photosynthesis-related proteins, TMT, Morphology, Differential proteomics

\section{Background}

Polyploidy is a prevalent biological phenomenon in the chromosomal evolution of extant species and genera $[1,2]$, including the major crop plants such as rice, maize, wheat, soybean, and cotton. Most plant species have polyploid ancestries [3], and polyploidy may have played a critical role

\footnotetext{
*Correspondence: ruans11@hotmail.com; hzhsma@163.com

${ }^{\dagger}$ Equal contributors

'Laboratory of Plant Molecular Biology \& Proteomics, Institute of

Biotechnology, Hangzhou Academy of Agricultural Sciences, Hangzhou

310024, China

Full list of author information is available at the end of the article
}

in flowering plant diversification [4]. Polyploid genotypes may lead to the differences in morphology, physiology and molecular characteristics, etc. Physiological traits, such as cell size, plant height $(\mathrm{PH})$, growth rate, flowering time and fertility, can be altered by polyploidization [5]. Miller and coworkers' research suggests that ploidy can affect flower size, stomatal size and seed weight [6]. Compared with the corresponding diploids (DPs), autopolyploids tend to have larger cells, resulting in the enlargement of some organs, such as leaves, flowers and seeds $[7,8]$. Chao and coworker discover that polyploid Arabidopsis exhibit resistance to salinity and higher potassium uptake [9]. Some other 
changed traits, such as pest resistance, apomixes, drought tolerance, flowering time and organ size, can also contribute to the success of polyploids in agriculture $[10,11]$.

Besides offering evolutionary flexibility and phenotypic diversity for newly formed polyploids, polyploidy has considerable impacts on chromosomal rearrangement, nuclear enlargement and epigenetic changes, leading to the restructuring of the transcriptome, metabolome and proteome [12]. The epigenetic and developmental alterations allow polyploids to establish new species and promote their niches in local environments through restructuring genome and regulatory networks [13]. Polyploidy plays a key role in duplicating gene expression, and many of these expression alterations are organ-specific [14]. Blanc and Wolfe propose that the functional diversification of duplicated genes is a major characteristic of long-term polyploidy events in Arabidopsis thaliana [15]. Polyploidy also has important impacts on genome structure and gene expression [16, 17]. DNA methylation changes are observed in allopolyploids and their progenitors in many plants [18-21]. However, little is known about the complex nature of polyploidy [22].

Interestingly, large differences in morphology and physiology, including $\mathrm{PH}$, leaf size and color, and chlorophyll content, are shown among rice with different ploidies, such as haploid (HP), DP and triploid (TP) rice. Besides, these differences are obviously amplified by the increase of ploidy level. The gene expression differences between HP and DP rice have been well documented [23], and the proteomic alterations during rice hull development are demonstrated by our recent research [24]. However, the proteomic changes between DP and TP in rice are poorly understood.

Thus, to test the impacts of polyploidy on rice development and chloroplast protein expression, we used tandem mass tags (TMT)-based proteomic methods to quantitatively screen the differentially expressed proteins among DP and TP. Meanwhile, chloroplast proteins were further analyzed to evaluate the influences of photosynthesis on DP and TP rice plants. In addition, quantitative real-time PCR (qRT-PCR) was used to verify the reliability of the chloroplast-related proteins with differential expressions. Through these approaches, our results may provide a global insight into the associated proteomic alterations in chloroplast and the impacts of ploidy on rice traits.

\section{Results}

\section{Phenotypes of DP and TP}

To identify the phenotypes of rice plants between DP and TP, nuclear DNA ploidy analysis was firstly performed by flow cytometry to identify DP and TP (Fig. 1b). The increases of PH, LL and LW were positively correlated with ploidy levels (Fig. 1). The values of PH, LL and LW in TP were significantly larger than those in DP (Fig. 1c, d, e).
Similarly, the contents of chlorophyll and carotenoid were higher in TP than in DP (Fig. 2).

\section{Comparative proteomic analysis of biological process in DP and TP}

Of the 1256 identified proteins, 365 differentially expressed proteins (fold change $>1.5$ ) showed the global false discovery rate $<0.01$ with $\geq 95 \%$ confidence. Compared with their expressions in DP, 311 proteins were upregulated and 54 were down-regulated in the TP. To uncover the different biological mechanisms between DP and TP, we annotated the differentially expressed proteins with GO terms and conducted a GO biological process. Multiple significant biological process were found to be involved in the differentially expressed proteins between DP and TP (Fig. 3), including generation of precursor metabolites and energy (GO:0006091, $p=8.96 \times 10^{-11}$ ), photosynthesis (GO:0015979, $p=5.2 \times 10^{-7}$ ), metabolic process (GO:0008152, $p=2.13 \times 10^{-6}$ ), response to abiotic stimulus (GO:0009628, $p=2.3 \times 10^{-6}$ ), response to stress (GO:0006950, $\quad p=8.04 \times 10^{-5}$ ), carbohydrate metabolic process (GO:0005975, $p=1.2 \times 10^{-4}$ ), and catabolic process (GO:0009056, $p=0.0494)$.

\section{Pathway analysis}

To identify potential protein targets, we performed pathway analysis on differentially expressed proteins using KEGG databases in rice plants with DP and TP (Fig. 4). Our results demonstrated that 16 significant pathways were enriched at the $5 \%$ significant level. Among these significant pathways, photosynthesis, metabolic pathways, glyoxylate and dicarboxylate metabolism, and carbon fixation in photosynthetic organisms were highly significant $(p<0.001)$ associated with the differentially expressed proteins between DP and TP. Both photosynthesis and metabolic pathways were found to be related to alterations of protein expression in the development between DP and TP according to GO biological process and pathway enrichment analysis.

\section{Analysis of differentially expressed chloroplast proteins and $\mathrm{qRT}$-PCR validation}

Chloroplast plays a crucial role in conducting photosynthesis and regulating and regulating metabolic biological process. To demonstrate the roles of chloroplast in rice ploidy, we studied the protein expression alterations in the chloroplasts of DP and TP. Chloroplast proteins CYB6, ribulose bisphosphate carboxylase large chain (RBL), Apocytochrome $\mathrm{f}$ (CYF), 3 ATP synthase subunits ATPA, ATPB and ATPF, 4 photosystem II reaction center proteins PSBB, PSBC, PSBD and PSBH, as well as 3 photosystem I related proteins PSAA, PSAB and PSAC were shown to have differentially up regulated in TP compared with DP (Table 1). None of these chloroplast proteins was differentially 


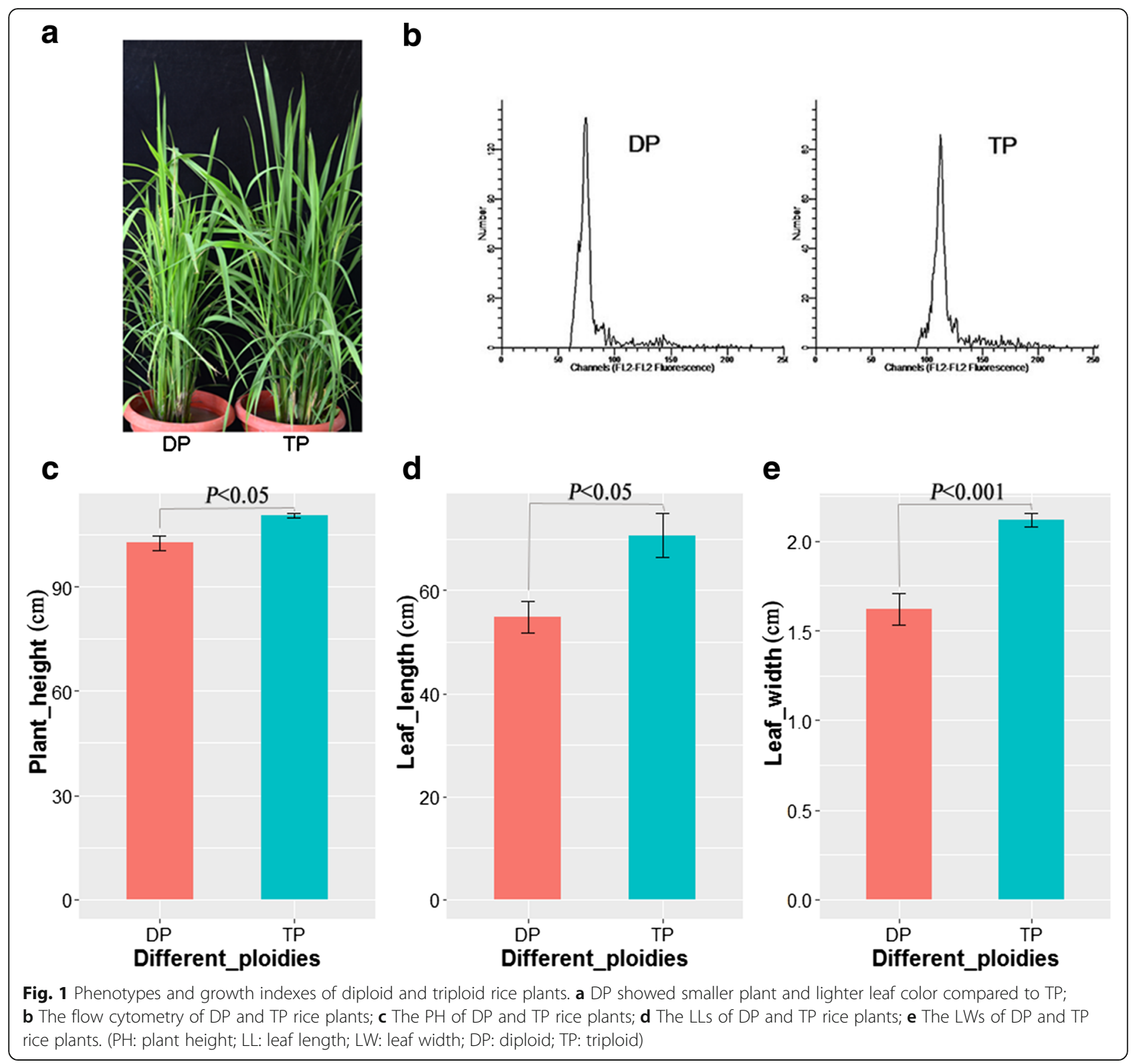

down-regulated in TP. Among these chloroplast proteins, 12 and 13 proteins were involved in photosynthesis and metabolic pathways, respectively; while three, one and one proteins were associated with oxidative phosphorylation, glyoxylate and dicarboxylate metabolism, and carbon fixation in photosynthetic organisms, respectively.

qRT-PCR was performed to validate the transcriptional levels for differentially expressed proteins among DP and TP (Fig. 5). qRT-PCR results showed that five of the 13 chloroplast genes were differentially transcripted between TP and DP, including ATPF, PSAA, PSAB, PSBB and $R B L$ (Fig. 5). All five genes were associated with metabolic pathways, and ATPF, PSAA, PSAB and PSBB were related to photosynthesis.

\section{Discussion}

Ploidy is a common feature and major factor of plant speciation. It drives the evolution of novel phenotypes and ecological tolerances [25]. Although the identification of candidate genes and developmental regulations in plant polyploids have been extensively pursued [16, 17, 23], a clear picture of proteins and pathways involved in regulatory and developmental differentiations has not been drawn for ploidy rice plants. In this study, our results suggests that proteomic alterations may account for the diversifications caused by ploidy in rice, and the significantly differentially expressed proteins and enriched pathways may help to unravel the complex underlying mechanisms in rice ploidy. Multiple pathways, especially photosynthesis and metabolic pathways, were 

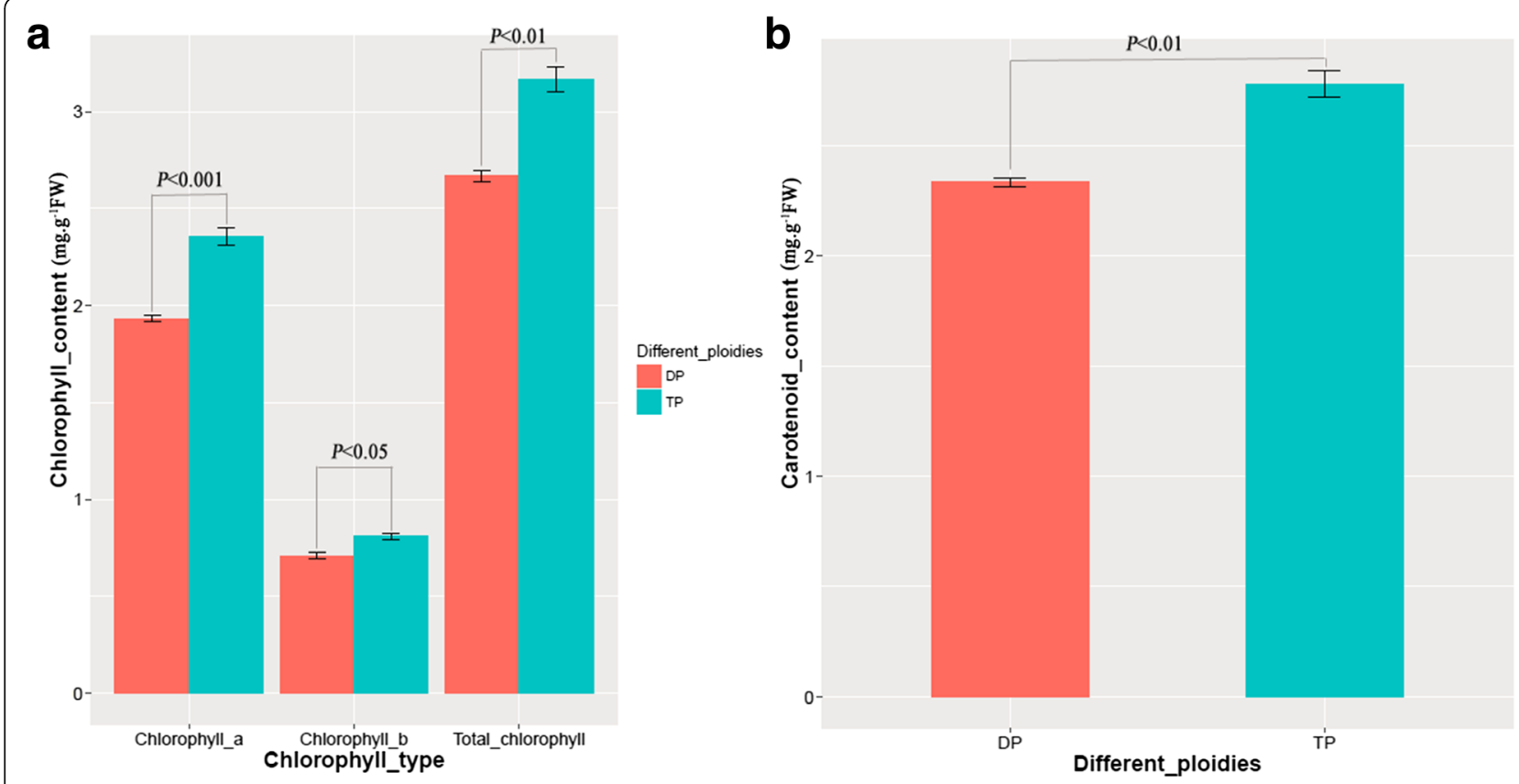

Fig. 2 The chlorophyll and carotenoid contents of diploid and triploid rice plants. a The chlorophyll contents of DP and TP rice plants; $\mathbf{b}$ The carotenoid contents of DP and TP rice plants. DP: diploid; TP: triploid

found to be greatly significantly associated with proteomic alterations between DP and TP, indicating that photosynthesis and metabolic pathways account for major contribution to the proteomic differentiation.

Accumulating evidence demonstrates that chloroplasts participate in a variety of complex signaling pathways to regulate plant development, photosynthesis and metabolism with a exquisite way [26]. In Arabidopsis, chloroplast potassium efflux antiporters influence photosynthesis and growth of fully developed rosettes [27]. The critical role of chloroplasts is beyond dispute and has been reported in plant immunity recently $[28,29]$. Recently, a chloroplast-

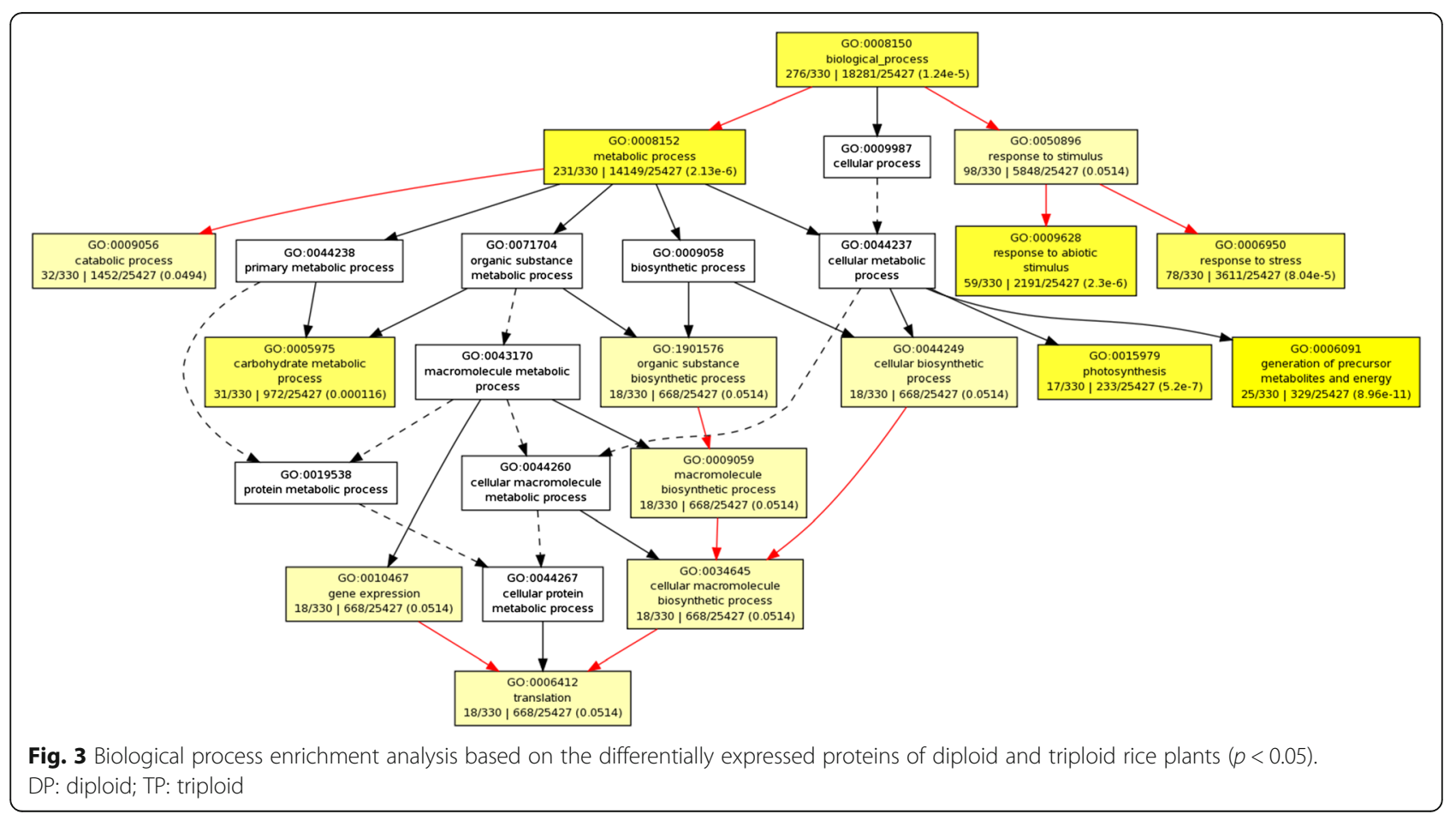




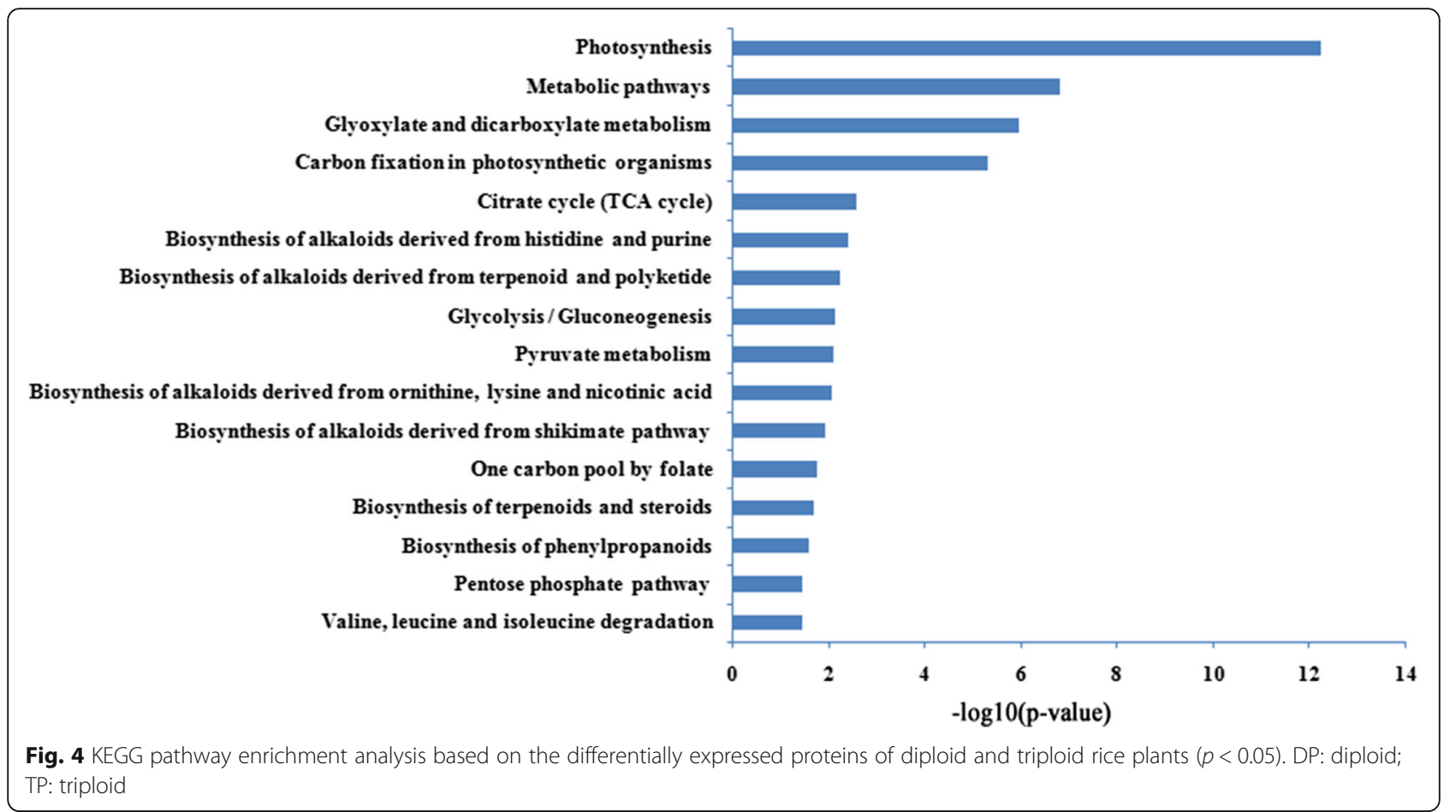

localized protein LLB was found to affect the growth in rice [30]. Although it is well known that chloroplast affects the growth of rice, the underlying molecular mechanisms are not yet understood clearly. Consistent with the higher chlorophyll content in TP, 13 significantly differentially expressed chloroplast proteins were found to be up- regulated in TP, and 5 proteins were validated by qRT-PCR. Cytochrome $b c$ complexes play key roles in respiration and photosynthesis [31]. The differential expression of CYB6 between the rice with different ploidies indicates that it may participate in energy transduction in respiratory membranes and photosynthesis. Among these validated

Table 1 The pathways participated by the differentially expressed chloroplast proteins between diploid and triploid rice plants

\begin{tabular}{|c|c|c|c|}
\hline Protein Name & Description & Pathways & $\mathrm{FC}^{f}$ \\
\hline CYB6 & Cytochrome b6 & osa00195; ;osa01100 & 1.80 \\
\hline TPB & $\begin{array}{l}\text { ATP synthase subunit beta, chloroplastic (EC 3.6.3.14) (ATP synthase F1 sector subunit beta) } \\
\text { (F-ATPase subunit beta) }\end{array}$ & $\begin{array}{l}\text { osa00190c }{ }^{c} \text { osa00195; } \\
\text { osa01100 }\end{array}$ & 1.79 \\
\hline RBL & Ribulose bisphosphate carboxylase large chain (RuBisCO large subunit) (EC 4.1.1.39) & $\begin{array}{l}\text { osa00630 }{ }^{\mathrm{d}} \text {;osa00710 } \\
\text { osa01100 }\end{array}$ & 1.99 \\
\hline $\mathrm{PSBH}$ & Photosystem II reaction center protein H (PSII-H) (Photosystem II 10 kDa phosphoprotein) & osa00195; osa01100 & 2.84 \\
\hline CYF & Apocytochrome $f$ & osa00195; osa01100 & 1.66 \\
\hline PSBD & Photosystem II D2 protein (PSII D2 protein) (EC 1.10.3.9) (Photosystem Q(A) protein) & osa00195 osa01100 & 2.15 \\
\hline PSBC & Photosystem II CP43 reaction center protein (PSII 43 kDa protein) (Protein CP-43) (Protein P6) & osa00195; ;osa01100 & 1.97 \\
\hline PSBB & Photosystem II CP47 chlorophyll apoprotein (PSII 47 kDa protein) (Protein CP-47) & osa00195; osa01100 & 1.71 \\
\hline PSAC & $\begin{array}{l}\text { Photosystem I iron-sulfur center (EC 1.97.1.12) (9 kDa polypeptide) (PSI-C) } \\
\text { (Photosystem I subunit VII) (PsaC) }\end{array}$ & osa00195 osa01100 b & 2.60 \\
\hline PSAB & Photosystem I P700 chlorophyll a apoprotein A2 (EC 1.97.1.12) (PSI-B) (PsaB) & osa00195; osa01100 & 2.09 \\
\hline PSAA & Photosystem I P700 chlorophyll a apoprotein A1 (EC 1.97.1.12) (PSI-A) (PsaA) & osa00195; ;osa01100 & 1.64 \\
\hline ATPA & $\begin{array}{l}\text { ATP synthase subunit alpha, chloroplastic (EC 3.6.3.14) (ATP synthase F1 sector subunit alpha) } \\
\text { (F-ATPase subunit alpha) }\end{array}$ & $\begin{array}{l}\text { osa00190c }{ }^{c} \text { osa00195 } \\
\text { osa01100 }\end{array}$ & 1.79 \\
\hline ATPF & ATP synthase subunit b, chloroplastic (ATP synthase $F(0)$ sector subunit b) (ATPase subunit I) & $\begin{array}{l}\text { osa00190c;osa00195a; } \\
\text { osa01100 }\end{array}$ & 2.74 \\
\hline
\end{tabular}

${ }^{a}$ Osa00195 represents photosynthesis; ${ }^{b}$ osa01100 represents metabolic pathways; ${ }^{c}$ osa00190 represents oxidative phosphorylation; ${ }^{d}$ osa00630 represents glyoxylate and dicarboxylate metabolism; ${ }^{\mathrm{e}}$ osa00710 represents carbon fixation in photosynthetic organisms; ${ }^{\mathrm{f}} \mathrm{FC}$ fold change 


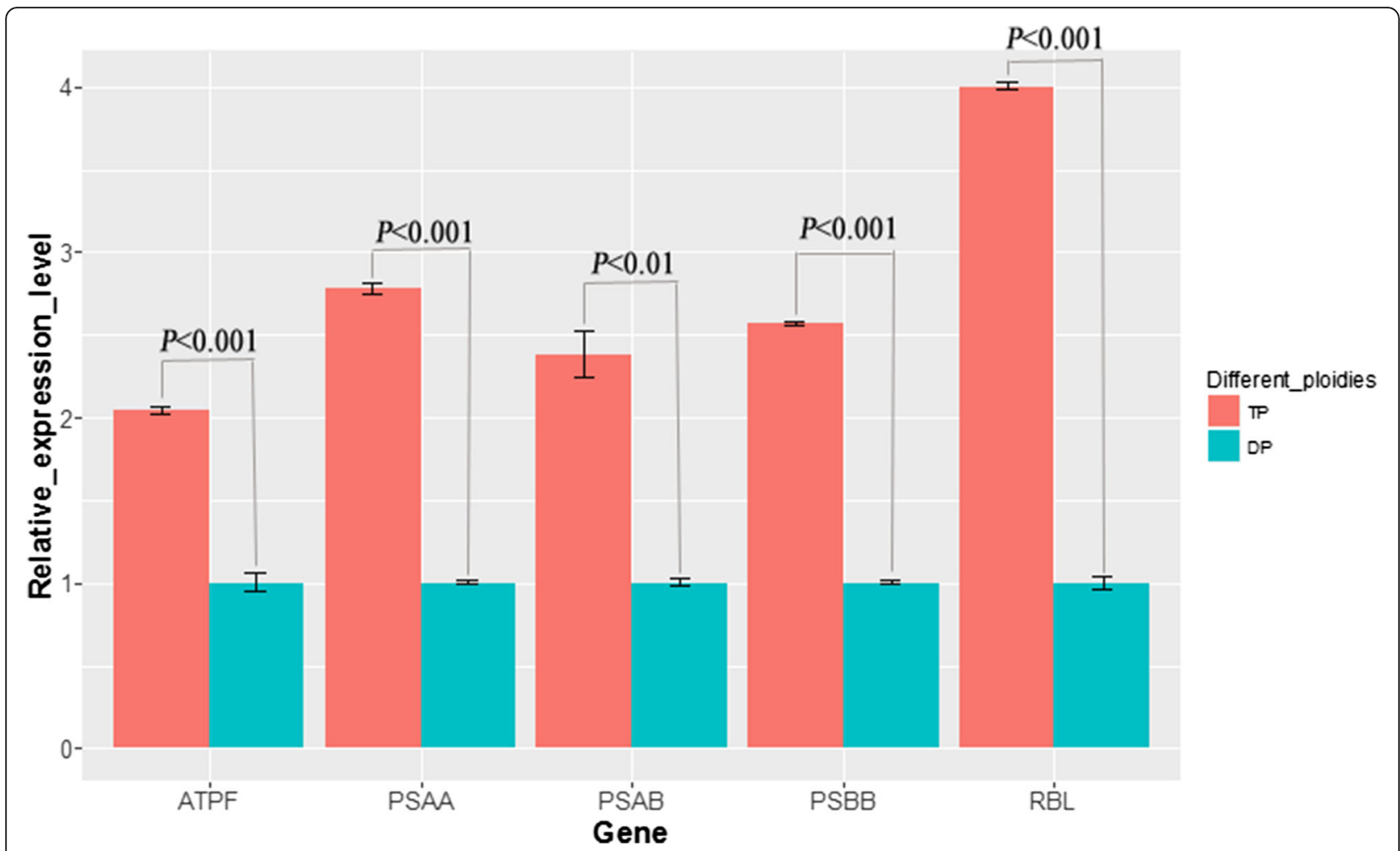

Fig. 5 Independent validation of the differentially expressed chloroplast proteins by qRT-PCR between diploid and triploid rice plants $(p<0.05)$

proteins, ATPF belongs to a plant-specific protein family and is characterized by CRM domain, a recognized RNA binding domain [32]. RBL is a RubisCO large subunit, and the most abundant protein that serving as the major engine for carbon assimilation [33]. It underlines that TP may improve the efficiency of photosynthesis via coupling with the reaction of RBL. PSAA, PSAB, and PSBB are components of the photosystem II core complex which is a critical element of photosynthesis [34]. Currently, little is known about the functions of PSAA, PSAB and PSBB.

To the best of our knowledge, this is the first study to analyze the proteomic alterations of rice plants with different ploidies using TMT MS/MS technology. Our analysis suggested that TP tended to maintain their needs via more photosynthesis and metabolic activities than DP. Among the 13 candidate chloroplast proteins, 5 were validated. Through the combination of morphology, physiology and proteomic profiling, our results characterize the function of ATPF, PSAA, PSAB, PSBB and RBL in TP, and provide new insights for further understanding the molecular characteristics of rice ploidy.

\section{Conclusions}

Both photosynthesis and metabolic pathways were highly significantly associated with proteomic alteration between DP and TP based on biological process and pathway enrichment analysis, and 13 up-regulated chloroplast proteins involving in these two pathways were identified in TP. This study integrates morphology, physiology and proteomic profiling alteration of DP and TP to address their underlying different molecular mechanisms. Our findings show that ATPF, PSAA, PSAB, PSBB and RBL can induce considerable expression changes in TP and may affect the development and growth of rice through photosynthesis and metabolic pathways.

\section{Methods \\ Plant materials}

To investigate the proteomic changes among rice plants with different ploidies, we sampled the leaves from eighty-day-old rice plants of DP and TP. Late uninucleate anthers collected from a rice strain (O. sativa $s s p$ japonica cv H14) that was supplied by Jiaxing Academy of Agricultural Sciences (Jiaxing, China) using microscopic identification were cultured at $27^{\circ} \mathrm{C}$ under the condition of $12 \mathrm{~h}$ light/dark photoperiod at light intensity of $2000 \mathrm{~lx}$ for one and half month on dedifferentiation medium containing N6, $1.0 \mathrm{mg} / \mathrm{l}$ 2,4-D, $3.0 \mathrm{mg} / \mathrm{l} \mathrm{NAA}$, $5.0 \mathrm{mg} / \mathrm{l} \mathrm{KT}, 5 \%(\mathrm{~m} / \mathrm{v})$ sucrose and $0.8 \%(\mathrm{~m} / \mathrm{v})$ agar to produce calli with haploid cells. Then calli were transferred and cultured under the same conditions as above for two and half weeks on the differentiation medium with the same formula as dedifferentiation medium to 
regenerate the haploid seedlings. By spontaneous chromosome doubling, doubled haploid seedlings were produced, which could be grown into a doubled haploid (DP) plants. In the doubling process, a small amount of TP plants were obtained. All rice plants were cultivated in field during the period from June 15th, 2013 to October 10th, 2013. Three experimental replicates of each rice line were tested.

\section{Measurement of plant height (PH), leaf length (LL) and width (LW)}

The heights of four replicates of 10 fifty-day-old plants were measured. Plant height was calculated by the distance from the basal part of stem to the tip of the highest leaf. The lengths and widths of 10 leaves from four replicates of fifty-day-old plants for each rice ploidy were measured. The standard errors (SE) of mean PH, LL or LW were calculated.

\section{Ploidy identification}

A total of $20 \mathrm{mg}$ of young leaf tissues were chopped with sharp scalpel in glass petri dish with $1 \mathrm{ml}$ of Otto I buffer containing $0.1 \mathrm{M}$ citric acid and $0.5 \%$ Tween-20. The chopped materials were filtered with a $350 \mu \mathrm{m}$ nylon filter and incubated for $10 \mathrm{~min}$ by stirring. Then, the nuclei in the filtrate were pelleted by centrifugation for $5 \mathrm{~min}$ at $150 \times \mathrm{g}$, resuspended in $200 \mu \mathrm{l}$ of Otto I buffer, and incubated at room temperature for $10 \mathrm{~min}$. Subsequently, $500 \mu \mathrm{l}$ of Otto II buffer containing $0.4 \mathrm{M}$ sodium hydrogen phosphate, $5 \mu \mathrm{M}$ propidium iodid (PI) and $50 \mu \mathrm{g} / \mathrm{ml}$ RNase was added to stain DNA. Samples were then analyzed within $1 \mathrm{~h}$ or stored at $4{ }^{\circ} \mathrm{C}$ for $24 \mathrm{~h}$. All samples were analyzed with a Cell Lab Quanta ${ }^{\mathrm{TM}} \mathrm{SC}$ (Beckman Coulter Inc.) flow cytometer equipped with $488 \mathrm{~nm}$ diode laser for excitation. Data were collected by the corresponding software.

\section{Determination of chlorophyll contents}

The contents of chlorophyll a and chlorophyll b were directly measured from the crude chlorophyll extracts of flag leaves. A total of $0.2 \mathrm{~g}$ leaf tissues were homogenized in ethanol at $4{ }^{\circ} \mathrm{C}$ as described by Porra et al. [35]. The homogenates were centrifuged and their fluorescence at 662, 645 and $470 \mathrm{~nm}$ was measured with a UV2550 Spectrometer.

\section{Protein preparation}

One gram of fresh rice leaves were ground in liquid nitrogen and suspended in $5 \mathrm{ml}$ acetone with $10 \%(\mathrm{w} / \mathrm{v})$ trichloroacetic acid and $0.07 \%(w / v) \beta$-mercaptoethanol at $-20{ }^{\circ} \mathrm{C}$ for $1 \mathrm{~h}$, followed by centrifugation for $15 \mathrm{~min}$ at $35,000 \times g$. The pellets were resuspended in acetone with $0.07 \%(\mathrm{w} / \mathrm{v}) \beta$-mercaptoethanol, incubated at $-20{ }^{\circ} \mathrm{C}$ for $1 \mathrm{~h}$, and then centrifuged for $15 \mathrm{~min}$ at $4{ }^{\circ} \mathrm{C}$. This step was repeated for three times. Then, the pellets were lyophilized. The crude protein powders were solubilized in lysis buffer (8 M urea, $2 \mathrm{M}$ thiourea, 4 \% CHAPS, $0.5 \%$ ampholine (pH 3-10), $50 \mathrm{mM}$ DTT and $1 \mathrm{mM}$ PMSF) for $1 \mathrm{~h}$ at room temperature, followed by centrifugation for $15 \mathrm{~min}$ at $15,000 \times \mathrm{g}$. The supernatants were collected in $1.5 \mathrm{ml}$ tubes, and $40 \mu \mathrm{l}$ samples were used to detect protein concentrations by Bradford assay, with bovine serum albumin as the standard.

\section{Protein digestion and TMT labeling}

A total of $100 \mu \mathrm{g}$ of samples were digested during the FASP procedure [36], with little modification. Each sample was transferred to a $10 \mathrm{k}$ filter (Pall Corporation) and centrifuged at $10,000 \mathrm{~g}$ at $20{ }^{\circ} \mathrm{C}$ for $20 \mathrm{~min}$. A total of $200 \mu \mathrm{l}$ UA buffer ( $8 \mathrm{M}$ urea, $0.1 \mathrm{M}$ Tris- $\mathrm{HCl}, \mathrm{pH} 8.5$ ) was added, and the samples were centrifuged at 14,000 g for $20 \mathrm{~min}$ again. Then, the sediments were mixed with $200 \mu \mathrm{l} 100 \mathrm{mM}$ IAA in UA buffer and incubated at room temperature in darkness for an additional $40 \mathrm{~min}$. After that, IAA was removed by centrifugation at $14,000 \mathrm{~g}$ for $20 \mathrm{~min}$, diluted with $200 \mu \mathrm{l}$ UA buffer, and centrifuged twice. A total of $200 \mu \mathrm{l} 0.5 \mathrm{M}$ triethylammonium bicarbonate (TEAB) buffer ( $\mathrm{pH} 8.5)$ was added and the samples were centrifuged at $14,000 \mathrm{~g}$ for $20 \mathrm{~min}$. This step was repeated twice. Finally, the samples were digested at $37{ }^{\circ} \mathrm{C}$ for $20 \mathrm{~h}$, and peptides were collected by centrifugation at $16,000 \mathrm{~g}$. To increase the yield of peptides, the filter was washed twice with $500 \mu \mathrm{l} 0.5 \mathrm{M}$ TEAB buffer ( $\mathrm{pH} 8.5$ ). The peptide solutions were dried in vacuum concentrator.

The TMT labeling procedure was performed following the manufacturer's instructions (Thermo Fisher Scientific). Briefly, for each 6-plex experiment, the reaction mixtures contained $25 \mu \mathrm{l}$ TMT reagent and $75 \mu \mathrm{l}(80 \mu \mathrm{g})$ tryptic digest in TEAB buffer to ensure reagent's stability by limiting the organic (acetonitrile) content between 25 and $30 \%$ $(v / v)$. The peptides from DP and TP samples were labeled with reagents for three biological replicates. After labeling, the reaction mixtures were incubated at room temperature for $1.5 \mathrm{~h}$, and then $8 \mu \mathrm{l}$ of $5 \%$ hydroxylamine solution was added to quench the labeling reaction. Then the TMTmodified digest from 6-plex experiment was combined into one sample and dried in vacuum.

\section{Peptide fractionation with strong cation exchange (SCX) chromatography}

Sample fractionation was performed by SCX chromatography as previously described [37]. Briefly, the sample was resuspended in SCX buffer $\left(7 \mathrm{mM} \mathrm{KH}_{2} \mathrm{PO}_{4}, \mathrm{pH} 2.6\right.$, $30 \% \mathrm{ACN}$ ) and separated through $2.0 \times 50 \mathrm{~mm}$ polySULFOETHYL A HPLC column ( $5 \mu \mathrm{m}, 200 \AA$, PolyLC). Separation was performed by applying a gradient SCX buffer B $\left(7 \mathrm{mM} \mathrm{KH} \mathrm{PO}_{4}, 350 \mathrm{mM} \mathrm{KCl}, \mathrm{pH} \mathrm{2.6,} 30 \%\right.$ 
$\mathrm{ACN}$ ) from 0 to $50 \%$ in $30 \mathrm{~min}$ at a flow rate of $0.1 \mathrm{ml} /$ min, followed by 50 to $100 \%$ SCX buffer A gradients and then buffer B in 10 min using an Agilent 1100 quaternary pump outfitted with degasser and photodiode array detector (PDA) (Thermo Scientific). Samples were collected in 5 min increments, and dried under vacuum. Fractions were then redissolved with $1 \% \mathrm{FA}$ and combined into a total of seven samples based on their intensities from SCX chromatographic UV trace. These samples were then desalted by C18 SPE and dried under vacuum.

\section{MS/MS analysis}

RP-HPLC separation was performed on a nanoflow HPLC (Proxeon Biosystems, now Thermo Fisher Scientific) equipped with self-packed tip column $(75 \mu \mathrm{m} \times 150 \mathrm{~mm}$; $\mathrm{C} 18,3.0 \mu \mathrm{m}$ ) using a $120 \mathrm{~min}$ gradient at a flow rate of $300 \mathrm{nl} / \mathrm{min}$. Q-Exactive mass spectrometer (Thermo Fisher Scientific) was used and equipped with nanoelectrospray ion source (Proxeon Biosystems, now Thermo Fisher Scientific). Data were acquired in the data-dependent "top10" mode in which the ten precursor ions with most abundance were selected with high resolution $(70000$ at $\mathrm{m} / \mathrm{z}$ 200) from the full scan (300-1800 m/z) for HCD fragmentation. Precursor ions with singly charged or unassigned charge information were excluded. The resolution for MS/MS spectra was set to 17500 at $\mathrm{m} / \mathrm{z} 200$, target value was 2E5 (AGC control enabled) and isolation window was set to $2.0 \mathrm{~m} / \mathrm{z}$, with a lock mass option enabled for the 445.120025 ion [38]. The normalized collision energy was $29 \%$.

Protein identification and the relative quantitation criteria All MS/MS spectra were searched using the MaxQuant software [39]. The TMT tags on lysine residues, peptide $\mathrm{N}$ termini $(229.162932 \mathrm{Da}$ ) and the carbamidomethylation of cysteine residues $(57.02146 \mathrm{Da})$ were set as static modifications, while the oxidation of methionine residues $(+15.99492 \mathrm{Da})$ was set as variable modification. The missing of two cleavage sites was allowed. The tolerances of peptides and fragment ions were set at $10 \mathrm{ppm}$ and $20 \mathrm{ppm}$, respectively. The false discovery rate on peptides and proteins was fixed at no more than 0.01 . Reporter ion quantitation was based on the extraction of the TMT reporter ion signals of each peptide by MaxQuant software. Proteins were then quantified by summing reporter ion counts across all peptide matches, and then normalized by assuming equal protein loadings across all samples. We used the following criteria to identify the differentially expressed proteins among DP and TP: (1) These proteins must have been examined in all 3 MS preparations; (2) They must have been verified with the confidence greater than $95 \%$; (3) The fold changes of their expressions should $>1.5$ or $<2 / 3$, and the significant differences $(p<0.05)$ in $t$-test should be reached.

\section{Biological process, pathway statistical analyses}

Rice gene annotations were acquired from the Rice Annotation Project Database (RAP-DB) [40], the Michigan State University (MSU) Rice Genome Annotation [41] and UniProt [42]. Chloroplast proteins were identified from uniprot (www.uniprot.org). Gene Ontology (GO) [43] and GOEAST [44] were used for biological process analysis between DP and TP. The differentially expressed proteins between DP and TP were analyzed using KEGG pathway [45] to identify the molecular pathways that may have differential activities involved in DP and TP. Two-tailed Student's t-tests were conducted to determine whether there are differences between DP and TP, including plant height, leaf length, width, chlorophyll content, carotenoids level and mRNA abundance levels. All statistical analyses were performed in R environment, using several CRAN packages (http://cran.r-project.org/).

\section{Validation of protein expression by qRT-PCR}

Frozen leaf tissue was homogenized in liquid nitrogen using a mortar and pestle. Total RNA was extracted using Trizol according to the supplier's recommendation (Invitrogen, Karlsruhe, Germany). Residual DNA was removed with an RNase-free DNase (Fermentas, EU). One microgram total RNA was reverse-transcribed using $0.5 \mu \mathrm{g}$ of Oligo (dT) 20 and 200 units of ReverTra Ace (TOYOBO, Japan) following the supplier's recommendation. qRT-PCR assays were performed to validate the expression changes of chloroplast proteins among DP and TP. Relative gene expression levels were quantified based on cycle threshold $(\mathrm{Ct})$ values and normalized to the reference proteins Tubulin and glyceraldehydes 3-phosphate dehydrogenase. The experiment for each sample was repeated for three technique replicates and the qRT-PCR results were calculated by means of three replications. Gene expression levels were calculated by $2-^{\Delta \Delta \mathrm{Ct}}$ method. Six pairs of primers were designed for gene-specific transcript amplification (Additional file 1).

\section{Additional file}

Additional file 1: Six pairs of primers were designed for gene-specific transcript amplification. (DOC $25 \mathrm{~kb}$ )

\footnotetext{
Abbreviations

ATPA: ATP synthase subunit alpha; ATPB: ATP synthase subunit beta; ATPF: ATP synthase subunit b; CYB6: Cytochrome b6; CYF: Apocytochrome f; DP: Diploid; HP: Haploid; LL: Leaf length; LW: Width; MS: Mass spectrometry; PH: Plant height; PSAA: Photosystem I P700 chlorophyll a apoprotein A1; PSAB: Photosystem I P700 chlorophyll a apoprotein A2; PSAC: Photosystem I iron-sulfur center; PSBB: Photosystem II CP47 chlorophyll apoprotein; PSBD: Photosystem II CP43 reaction center protein; PSBE: Cytochrome b559 subunit alpha; PSBH: Photosystem II reaction center protein H; RBL: Ribulose bisphosphate carboxylase large chain; SCX: Strong cation exchange; TMT: Tandem mass tags; TP: Triploid
} 


\section{Acknowledgements}

This work was supported by the Great Project of Science and Technology of Hangzhou City (Research Grant \#20131812A02 to S.-L. R.), Zhejiang Provincial Natural Science Foundation of China (Research Grant \# LR12C13001 to S.-L. R.) and the Open Project of State Key Laboratory of Rice Biology (Research Grant $\# 12020313$ to S.-Z.W. and S.-L. R.).

\section{Funding}

1. Great Project of Science and Technology of Hangzhou, Award Number: 20131812A02 | Recipient: Songlin Ruan, Ph.D

2. Zhejiang Provincial Natural Science Foundation of China, Award Number: LR12C13001 | Recipient: Songlin Ruan, Ph.D

3. Open Project of State Key Laboratory of Rice Biology, Award Number: 12020313 | Recipient: Shuzhen Wang

\section{Availability of data and materials}

All the data supporting these findings is contained within the manuscript.

\section{Authors' contributions}

SZW carried out LC-MS/MS analysis. WYC carried out material preparation and phenotype analysis. JY and WFX carried out protein preparation and participated in LC-MS/MS analysis. CDY, YX and YPF carried out peptide fractionation. JRQ,WMH and WY carried out protein identification. HGY and JXT carried out protein mass spectrum hierarchical cluster analysis and statistical analysis. ZZC carried out gene ontology and pathway analysis. SLR conceived of the study, participated in its design and coordination and completed the manuscript. HSM participated in the design of the study. All authors read and approved the final manuscript.

\section{Competing interests}

The authors declare that they have no competing interests.

\section{Consent for publication}

Not applicable.

\section{Ethics approval and consent to participate}

No ethics approval and consent is required.

\section{Author details}

'Laboratory of Plant Molecular Biology \& Proteomics, Institute of Biotechnology, Hangzhou Academy of Agricultural Sciences, Hangzhou 310024, China. ${ }^{2}$ State Key Laboratory of Rice Biology, China National Rice Research Institute, Hangzhou 310006, China. ${ }^{3}$ Jiaxing Academy of Agricultural Sciences, Jiaxing 314016, China. ${ }^{4}$ Department of Agronomy, College of Agriculture and Biotechnology, Zhejiang University, Hangzhou 310012, China.

Received: 6 June 2016 Accepted: 6 September 2016

\section{Published online: 13 September 2016}

\section{References}

1. Otto SP, Whitton J. Polyploid incidence and evolution. Annu Rev Genet. 2000;34:401-37.

2. Mayrose I, Zhan SH, Rothfels CJ, Magnuson-Ford K, Barker MS, Rieseberg LH, Otto SP. Recently formed polyploid plants diversify at lower rates. Science. 2011:333(6047):1257.

3. Wood TE, Takebayashi N, Barker MS, Mayrose I, Greenspoon PB, Rieseberg $\mathrm{LH}$. The frequency of polyploid speciation in vascular plants. Proc Natl Acad Sci U S A. 2009;106(33):13875-9.

4. Jiao Y, Wickett NJ, Ayyampalayam S, Chanderbali AS, Landherr L, Ralph PE Tomsho LP, Hu Y, Liang H, Soltis PS, et al. Ancestral polyploidy in seed plants and angiosperms. Nature. 2011:473(7345):97-100.

5. Yao H, Kato A, Mooney B, Birchler JA. Phenotypic and gene expression analyses of a ploidy series of maize inbred Oh43. Plant Mol Biol. 2011;75(3):237-51.

6. Miller M, Zhang C, Chen ZJ. Ploidy and hybridity effects on growth vigor and gene expression in Arabidopsis thaliana hybrids and their parents. G3. 2012:2(4):505-13.

7. Abel S, Becker HC. The effect of autopolyploidy on biomass production in homozygous lines of Brassica rapa and Brassica oleracea. Plant Breed. 2007;126(6):642-3.
8. Li X, Yu E, Fan C, Zhang C, Fu T, Zhou Y. Developmental, cytological and transcriptional analysis of autotetraploid Arabidopsis. Planta. 2012;236(2):579-96.

9. Chao DY, Dilkes B, Luo H, Douglas A, Yakubova E, Lahner B, Salt DE. Polyploids exhibit higher potassium uptake and salinity tolerance in Arabidopsis. Science. 2013;341(6146):658-9.

10. Osborn TC, Pires JC, Birchler JA, Auger DL, Chen ZJ, Lee HS, Comai L, Madlung A, Doerge RW, Colot V, et al. Understanding mechanisms of novel gene expression in polyploids. Trends Genet. 2003;19(3):141-7.

11. Challagulla V, Bhattarai S, Midmore DJ. In-vitro vs in-vivo inoculation: screening for resistance of Australian rice genotypes against blast fungus. Rice Sci. 2015:22(3):132-7.

12. Leitch AR, Leitch IJ. Genomic plasticity and the diversity of polyploid plants. Science. 2008:320(5875):481-3.

13. Song Q, Chen ZJ. Epigenetic and developmental regulation in plant polyploids. Curr Opin Plant Biol. 2015:24:101-9.

14. Adams KL, Wendel JF. Novel patterns of gene expression in polyploid plants. Trends Genet. 2005:21(10):539-43.

15. Blanc $\mathrm{G}$, Wolfe $\mathrm{KH}$. Functional divergence of duplicated genes formed by polyploidy during Arabidopsis evolution. Plant Cell. 2004;16(7):1679-91.

16. Doyle JJ, Flagel LE, Paterson AH, Rapp RA, Soltis DE, Soltis PS, Wendel JF. Evolutionary genetics of genome merger and doubling in plants. Annu Rev Genet. 2008;42:443-61

17. Renny-Byfield S, Wendel JF. Doubling down on genomes: polyploidy and crop plants. Am J Bot. 2014;101(10):1711-25

18. Zheng $X$, Chen L, Lou Q, Xia H, Li M, Luo L. Changes in DNA methylation pattern at two seedling stages in water saving and drought-resistant rice variety after drought stress domestication. Rice Sci. 2014;21(5):262-70.

19. Tian L, Li X, Ha M, Zhang C, Chen ZJ. Genetic and epigenetic changes in a genomic region containing MIR172 in Arabidopsis allopolyploids and their progenitors. Heredity. 2014;112(2):207-14.

20. Kenan-Eichler M, Leshkowitz D, Tal L, Noor E, Melamed-Bessudo C, Feldman M, Levy AA. Wheat hybridization and polyploidization results in deregulation of small RNAs. Genetics. 2011;188(2):263-72.

21. Wang J, Tian L, Madlung A, Lee HS, Chen M, Lee JJ, Watson B, Kagochi T, Comai $\mathrm{L}$, Chen ZJ. Stochastic and epigenetic changes of gene expression in Arabidopsis polyploids. Genetics. 2004;167(4):1961-73.

22. Dufresne F, Stift M, Vergilino R, Mable BK. Recent progress and challenges in population genetics of polyploid organisms: an overview of current state-ofthe-art molecular and statistical tools. Mol Ecol. 2014;23(1):40-69.

23. Kathiresan A, Khush GS, Bennett J. Two rice DMC1 genes are differentially expressed during meiosis and during haploid and diploid mitosis. Sex Plant Reprod. 2002;14(5):257-67.

24. Wang S, Chen W, Xiao W, Yang C, Xin Y, Qiu J, Hu W, Ying W, Fu Y, Tong J, et al. Differential proteomic analysis using iTRAQ reveals alterations in hull development in rice (oryza sativa L.). PLoS One. 2015;10(7):e0133696.

25. Coate JE, Bar $\mathrm{H}$, Doyle JJ. Extensive translational regulation of gene expression in an allopolyploid (Glycine dolichocarpa). Plant Cell. 2014;26(1):136-50.

26. Bobik K, Burch-Smith TM. Chloroplast signaling within, between and beyond cells. Frontiers in plant science. 2015:6:781.

27. Dana S, Herdean A, Lundin B, Spetea C. Each of the chloroplast potassium efflux antiporters affects photosynthesis and growth of fully developed Arabidopsis rosettes under short-day photoperiod. Physiol. Plant. 2016. doi: 10.1111/ppl.12452

28. Nomura H, Komori T, Uemura S, Kanda Y, Shimotani K, Nakai K, Furuichi T, Takebayashi K, Sugimoto T, Sano S, et al. Chloroplast-mediated activation of plant immune signalling in Arabidopsis. Nat Commun. 2012;3:926.

29. Ishiga Y, Rao Uppalapati S, Gill US, Huhman D, Tang Y, Mysore KS. Transcriptomic and metabolomic analyses identify a role for chlorophyll catabolism and phytoalexin during Medicago nonhost resistance against Asian soybean rust. Sci Rep. 2015;5:13061.

30. Tamiru M, Takagi H, Abe A, Yokota T, Kanzaki H, Okamoto H, Saitoh H, Takahashi H, Fujisaki K, Oikawa K, et al. A chloroplast-localized protein LESION AND LAMINA BENDING affects defence and growth responses in rice. New Phytol. 2016;210(4):1282-97.

31. Dibrova DV, Cherepanov DA, Galperin MY, Skulachev VP, Mulkidjanian AY. Evolution of cytochrome bc complexes: from membrane-anchored dehydrogenases of ancient bacteria to triggers of apoptosis in vertebrates. Biochim Biophys Acta. 2013:1827(11-12):1407-27.

32. Ostersetzer O, Cooke AM, Watkins KP, Barkan A. CRS1, a chloroplast group II intron splicing factor, promotes intron folding through specific interactions with two intron domains. Plant Cell. 2005;17(1):241-55. 
33. Igamberdiev AU. Control of Rubisco function via homeostatic equilibration of CO2 supply. Frontiers in plant science. 2015;6:106

34. Lambert DH, Bryant DA, Stirewalt VL, Dubbs JM, Stevens Jr SE, Porter RD. Gene map for the Cyanophora paradoxa cyanelle genome. J Bacteriol. 1985;164(2):659-64.

35. Porra R, Thompson W, Kriedemann P. Determination of accurate extinction coefficients and simultaneous equations for assaying chlorophylls $a$ and $b$ extracted with four different solvents: verification of the concentration of chlorophyll standards by atomic absorption spectroscopy. Biochim Biophys Acta. 1989;975:384-94.

36. Wisniewski JR, Zougman A, Nagaraj N, Mann M. Universal sample preparation method for proteome analysis. Nat Methods. 2009;6(5):359-62.

37. Ting L, Rad R, Gygi SP, Haas W. MS3 eliminates ratio distortion in isobaric multiplexed quantitative proteomics. Nat Methods. 2011;8(11):937-40.

38. Gruhler A, Olsen JV, Mohammed S, Mortensen P, Faergeman NJ, Mann M, Jensen ON. Quantitative phosphoproteomics applied to the yeast pheromone signaling pathway. Mol Cell Proteomics. 2005;4(3):310-27.

39. Cox J, Mann M. MaxQuant enables high peptide identification rates, individualized p.p.b.range mass accuracies and proteome-wide protein quantification. Nat Biotechnol. 2008;26(12):1367-72.

40. Sakai H, Lee SS, Tanaka T, Numa H, Kim J, Kawahara Y, Wakimoto H, Yang CC, Iwamoto M, Abe T, et al. Rice Annotation Project Database (RAP-DB): an integrative and interactive database for rice genomics. Plant Cell Physiol. 2013:54(2):e6.

41. Ouyang S, Zhu W, Hamilton J, Lin H, Campbell M, Childs K, Thibaud-Nissen F, Malek RL, Lee Y, Zheng L, et al. The TIGR Rice Genome Annotation Resource: improvements and new features. Nucleic Acids Res. 2007; 35(Database issue):D883-887.

42. UniProt. Update on activities at the Universal Protein Resource (UniProt) in 2013. Nucleic Acids Res. 2013;41(Database issue):D43-47.

43. Gene Ontology C, Blake JA, Dolan M, Drabkin H, Hill DP, Li N, Sitnikov D, Bridges S, Burgess S, Buza T, et al. Gene Ontology annotations and resources. Nucleic Acids Res. 2013;41(Database issue):D530-535.

44. Zheng Q, Wang XJ. GOEAST: a web-based software toolkit for Gene Ontology enrichment analysis. Nucleic Acids Res. 2008;36(Web Server issue):W358-363.

45. Kanehisa M, Goto S. KEGG: kyoto encyclopedia of genes and genomes. Nucleic Acids Res. 2000;28(1):27-30

\section{Submit your next manuscript to BioMed Central and we will help you at every step:}

- We accept pre-submission inquiries

- Our selector tool helps you to find the most relevant journal

- We provide round the clock customer support

- Convenient online submission

- Thorough peer review

- Inclusion in PubMed and all major indexing services

- Maximum visibility for your research

Submit your manuscript at www.biomedcentral.com/submit

) Biomed Central 